\title{
NARIAL CLOSURE IN TOADS; WHICH MUSCLES?
}

\author{
CARL GANS and REBECCA PYLES
}

Division of Biological Sciences, University of Michigan, Ann Arbor, MI 48109, and Museum of Natural History, University of Kansas, Lawrence, KS 66045, U.S.A.

\begin{abstract}
Narial closure in frogs never involves intrinsic narial muscles; rather it is effected by action of the M. submentalis, a muscle of the lower jaw. None of more than 40 species of frogs examined showed any strained muscles in the snout, anterior to the eyes. Direct stimulation of all the relevant muscles, as well as electromyography with simultaneous measurement of air flow at the nostrils, confirms Gaupp's hypothesis that the muscular displacement of the M. submentalis is transmitted via bones and cartilages of the snout to close the nares.
\end{abstract}

$\begin{array}{ll}\text { Breathing } & \text { Nares } \\ \text { Closure } & \text { Nostril } \\ \text { Frog } & \text { Snout }\end{array}$

In the third edition of Ecker's Anatomie des Frosches, Gaupp (1898-1904, also 1896) discussed the mechanism by which species of Rana close their nostrils during the pulse pumping that powers ventilation. He proposed that closure was indirect, involving contraction of the $\mathrm{M}$. submentalis and consequent lifting of the mentomeckelian bones against the premaxillae. Rotation of the latter bones deforms the elastic alary cartilages and closes the nostrils. This explanation was generally accepted, and has been specifically redescribed on the basis of electromyographical results (de Jongh and Gans, 1969). In 1975 West and Jones proposed an alternative mechanism based upon (1) the occurrence of intrinsic narial muscles, (2) a claim that these muscles were striated (as implied in the first and second editions of Ecker; as well as by Shinkai and Narita, 1957) and (3) illustration of electrical signals recorded from the nares in synchrony with closing movements of the nostrils. The possibility that the mechanism proposed by Gaupp might need modification was made likely by apparently paradoxical effects claimed for the $M$. submentalis. This muscle depresses the mentomeckelian region during tongue 
propulsion (Gans and Gorniak, 1982), but lifts it during ventilation (de Jongh and Gans, 1969).

We here have reconsidered the two alternative mechanisms and tested them. Morphological and physiological evidence including several additional experiments indicate that the nostrils of frogs (1) lack intrinsic striated muscles and (2) are indeed closed by action of the M. submentalis. Analysis of electromyograms also indicates that the action of the latter muscle is differentially directed by the time course of contraction of the $\mathbf{M}$. geniohyoideus lateralis.

\section{Materials and methods}

Table 1 lists some 48 sets of serial sections of 41 species (including 31 genera) of frogs that were examined to determine whether their snouts contained significant musculature and to determine its possible location. For each we list its number in the Museum of Natural History at The University of Kansas. For all muscles observed we searched for any evidence of striation, estimated the relative mass, and also considered fiber direction relative to the narial aperture.

TABLE 1

Series examined. Sample size: 9 families, 31 genera, 42 species, 47 series.

Bufonidae

Bufo boreas

Bufo punctatus

Bufo quercicus

Bufo terrestris

Bufo valliceps

Bufo woodhousei

Centrolenidae

Centrolenella fleischmanni

Dendrobatidae

Dendrobates gramuliferus

Dendrobates pumilio

Hylidae

Agalychnis callidryas

Anotheca cornuta

Hyla crucifer

Hyla ebraccata

Psendacris triseriata

Leptodactylidae

Cycloramphus neglectens

Eleutherodactylus pygmaeus

\author{
186959 , female \\ 186952, male \\ 186958 , male \\ 186953, female \\ 186949, 186951, males \\ 186950 , male; 186955 , female
}

186978, male

186977, female

186976, female

186980, male

186983, female

R.G. Northcutt

186975, male

186926, female

186965 , female

186969 , female 
TABLE 1 continued

\begin{tabular}{|c|c|}
\hline Eleutherodactylus rugulosus & 186968,186973 , females \\
\hline Eupsophus roseus & 186911, female \\
\hline Leptodactylus labialis & 186966, male \\
\hline Limnomedusa macroglossa & 186751, male \\
\hline Lithodytes lineatus & 186972, male \\
\hline Physalaemus cuvieri & 186920,186974 , females \\
\hline Physalaemus pustulosus & 186963 , male; 186961 , female \\
\hline Sminthillus limbatus & 186977 , female \\
\hline Syrrhopus marnocki & 186962 , female \\
\hline Telmatobius jelskii & 186919 , male \\
\hline Tomodactylus nitidus & 186967, female \\
\hline \multicolumn{2}{|l|}{ Microhylidae } \\
\hline Hypopachus variolosus & 186985,186987, males \\
\hline \multicolumn{2}{|l|}{ Myobatrachidae } \\
\hline Adelotus brevis & 186971, female \\
\hline Crinia signifera & 186928, female \\
\hline Cyclorana alboguttata & 186929 \\
\hline Geocrinia laevis & 186934 \\
\hline Heleophryne purcelli & 186744, female \\
\hline Limnodynastes fletcheri & 186981 , female \\
\hline Limnodynastes ornatus & 186964 , female \\
\hline Mixophryes fasciolatus & 186979 , male \\
\hline Neobatrachus pictus & 186941 , female \\
\hline Philoria frosti & 186943, unsexed \\
\hline Pseudophryne semimarmorata & 186948, female \\
\hline \multicolumn{2}{|l|}{ Pelobatidae } \\
\hline Scaphiopus holbrooki & 186982 , female \\
\hline \multicolumn{2}{|l|}{ Ranidae } \\
\hline Rana 'pipiens' & 186906 \\
\hline Rana sylvatica & 186908 \\
\hline
\end{tabular}

The nasal regions of two adult Bufo marinus (400-500 g) were dissected free and dissolved in nitric acid, an approach that dissolves the connective tissue prior to muscle fibers. Interruption of digestion by placement of the specimens in glycerin permitted their examination under a compound microscope to determine unequivocally whether they are smooth or striated (William and Goldspink, 1971). A slip of striated muscle from the $\mathbf{M}$. depressor mandibulae was examined for comparison.

A fine pin was placed on each side of the submental muscles of four adult toads (Bufo marinus) that were recovering from 10-30\% alcohol anesthesia. Stimulation voltages were $0.5-3 \mathrm{~V}$, frequencies $20-30 \mathrm{~Hz}$, and durations $5-10 \mathrm{msec}$. Paired stimulation electrodes were used to apply equivalent (and greater) voltages to 
various sites in the snout in the vicinity of the $M$. lateralis narium and medialis narium. A simple narial closure indicator, utilizing a make-break DC contact glued to the narial lips with a dental adhesive (Permlastic), as well as split-screen recording of narial movements and records of stimulation voltages on a video tape system ( $24 \mathrm{fps}$ ) established the coincidence of movements.

Fine-wire bipolar steel electrodes (Gans and Gorniak, 1980) were placed in various positions near the site of the $M$. lateralis narium in an attempt to record electromyograms (EMGs). Twisted fine-wire electrodes (0.003-inch stainless steel, teflon coated) were placed into the M. submentalis of four adult Bufo marinus and the signals differentially amplified on a Tektronix 26A2 and stored on magnetic tape (as described in Gans and Gorniak, 1982). Paired tubes placed over the nostrils were connected to a miniature flow meter (Gans and Clark, 1978) and its output stored in parallel to the EMG signal.

\section{Results}

Examination of hematoxylin- and eosin-stained serial sections of the frogs listed in Table 1 disclosed no obvious striated muscle in the upper jaw anterior to the eye. Some species appear to have two small smooth muscles in the vicinity of the external nares. The M. lateralis narium (Gaupp, 1898-1904) appeared as a very small patch of apparently smooth muscle fibers generally in the anterolateral wing of the nostril (varying intraspecifically), always placed adjacent to various narial glands. However, a Bodian-stained series of Hyla crucifer disclosed only connective tissue fibers and neither smooth nor striated muscles anterior to the eye. No fibers lay in a position where they could have effected major movements of the narial cartilages, such as those observed superficially during ventilatory cycles (de Jongh and Gans, 1969). Not only the placement but also the bulk of the fibers would have been insufficient to effect the movements.

Examination of dissolved tissues of Bufo marinus disclosed no indication of striated fibers; other (striated) frog muscles dissolved for comparison showed obvious banding.

Placement of fine-wire electrodes in the narial region disclosed no signals that could be interpreted as electromyograms, nor did stimulation of the region of the $\mathrm{Mm}$. lateralis and medialis narium (even at levels of more than $10 \mathrm{~V}$ and 3-50 cycles, which caused the eyelids to blink, apparently due to the spread of the stimulus) disclose any obvious twitch, and certainly no narial closure.

In contrast, stimulation of the $\mathrm{M}$. submentalis ( $1-3 \mathrm{~V}, 30 \mathrm{~Hz}, 5-10 \mathrm{msec}$ pulses) produced obvious and marked contraction of this muscle reflected by approximation of the mandibular tips and elevation of the symphysial region. Stimulus onset was always coincident with full closure of the external nares. A twitch of the muscle induced a twitch of the nares, while stronger muscular contractions blinked the nares closed. Stimulation at lower voltages induced partial closure. 
The stimulus signal could be detected (at a level of about $10 \%$ of that applied to the mandibular region) by a pair of fine-wire electrodes placed adjacent to the naris. This effect was not significantly attenuated when a plastic sheet was used to separate the moist mucous surfaces of upper and lower jaws. However, stimulation of the M. intermandibularis posterior also produced signals from the narial region without any narial closure.

EMGs from the M. submentalis, recorded while tubes from a flow-meter intercepted the airstream opposite both narial openings, disclosed that these signals always coincided with an interruption of air flow (fig. 1). Slight signals induced apparent flow reduction, strong pulses stopped flow completely. Several adventitious placements of electrodes into adjacent muscles ( $\mathrm{Mm}$. intermandibularis posterior, genioglossus) yielded EMGs that did not coincide with narial closure; hence,

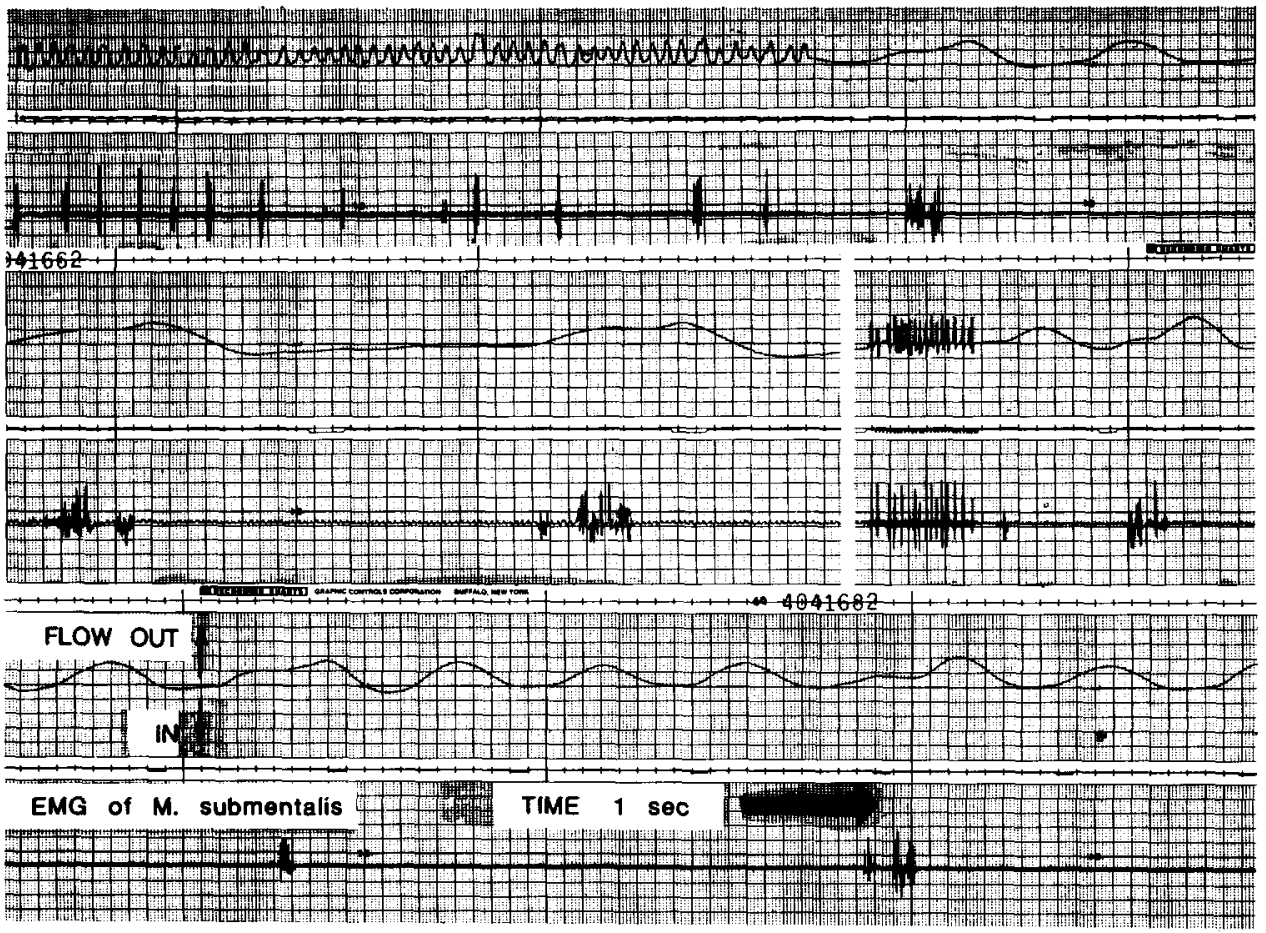

Fig. 1. Four sample sections showing recordings at different speeds of (top) airflow measured opposite the nares, (middle) timed signal indicating $1 \mathrm{sec}$ markings and (bottom) electromyograms from the submentalis muscle of Bufo marinus. Note that the airflow records include simple buccal oscillations characterized by smoothly rounded inflow and outflow curves that are never associated with electromyographic activity in the $\mathrm{M}$. submentalis. A second category of oscillations shows interrupted flow noted as truncations of the flow curves. These always coincide with the electromyographic activity. The former oscillations are interpreted as buccal oscillations (de Jongh and Gans, 1969), the latter as ventilation cycles. The association between EMG and airflow was absolute over all the hundreds of cycles recorded. 
the correlation was most specific. It should be stressed that the flow was recorded on some toads that were still mildly tranquilized and others that were frightened. Furthermore, we noted that complete occlusion of the external naris by the tube of the flow-meter tends to induce artifacts of the kind noted by Clark et al. (1978). The flow-meter apertures were thus placed opposite, but slightly away from the nostrils, leading to some hysteresis in the flow detection pattern. However, the $\mathbf{M}$. submentalis fired when the nostrils closed, both in ventilation cycles and in inflation ones.

\section{Discussion}

The above results suggest unequivocally that the closure of the nares is associated with action of the M. submentalis. This makes it most likely that the movement starts with upward swelling of the M. submentalis, with its displacement transmitted through a complex linkage from the mentomeckelians to the alary cartilages. Upon relaxation of the $M$. submentalis the intrinsic elasticity of the alaries apparently restores a patent naris. There are no intrinsic narial muscles capable of effecting closure. This confirms the observations of Gaupp (1896, 1898-1904), Bruner (1901, 1914a,b) and other investigators (such as de Jongh and Gans, 1969; Shinkai and Narita, 1957) who confirmed his work on various species of Bufo and Rana.

The proposal of West and Jones (1975) is based upon three bits of evidence. The first is the report of intrinsic narial muscles in Haslam's translation of the second edition of Ecker (1889). (It is regrettable that this, rather than the completely revised and more extensive third edition, edited by Gaupp, 1898-1904, has recently been reprinted.) The second is reference to the report by Shinkai and Narita (1957) of striated muscles in the naris of 'a [Japanese] toad', and the third are the electrical recordings published in West and Jones (1975; also ascribed to Jones, 1970 , which does not specifically name this muscle).

Examination of the regions of the $\mathbf{M}$. lateralis narium in various frogs (Table 1) discloses a mass that might contain a few muscle fibers, but no traces of striation were found; as noted these were drastically different from the fibers of the truly striated muscles examined for comparison. The Bodian-stained series of $H y l a$ crucifer showed neither smooth nor striated muscles. The reference to Shinkai and Narita (1957) is furthermore misleading. These authors did state "We could find tissues like striated muscle fibers around the caritilago [sic] nasi in a few preparations..."; however, they neither provided figures nor detailed their histological techniques. They remarked in the same article (Shinkai and Narita, 1957) that no spike discharges were observed from these fibers during respiration. On the basis of denervation experiments they furthermore concluded that the action of the $\mathbf{M}$. submentalis closed the nares. Even Bruner, 1914, who carried out extensive studies on the smooth muscles and connective tissues of this region, observed that closure was by "a system of levers under the control of striated muscles". This leaves no 
grounds for questioning Gaupp's unequivocal statement that the narial muscles of Rana are smooth and not involved in narial closure.

This leaves only the illustration of physiological recordings from the region of the M. lateralis narium to be explained (West and Jones, 1975, fig. 1). West and Jones refer to the use of separate, rather than mechanically joined, copper wires, and perhaps to their individual insertion (Jones, 1970). If placed into connective tissues, such an electrode array might generate movement artifacts and detect signals from powerful muscles that are some distance removed. The signals of our stimulating electrodes in the lower jaw could indeed be detected at the nares, even when the mouth was filled with a dielectric material. While this may document the occurrence of bulk conduction, the lack of closing action noted when the stimulus was applied to the $\mathbf{M}$. intermandibularis posterior, rather than the $\mathbf{M}$. submentalis, eliminates the possibility that the stimulus could have coincidentally triggered some as yet undescribed muscles of the nares.

While the force for closing the external nares is produced by the $M$. submentalis in all higher frogs examined thus far, the mechanism in such 'archaic' forms as Xenopus and Pipa deserves further attention. Indeed, occurrence of a smooth $\mathrm{Mm}$. lateralis and medialis narium has been documented thus far only for species of Rana (Gaupp, 1896, 1889-1904). Gaupp specifically discounted the earlier (i.e., Dugès, 1834) claims for striated nostril-closing muscles, and used the report of Bruner (1901, also $1914 \mathrm{a}, \mathrm{b})$ to refer to muscles involved in the maintenance of an open

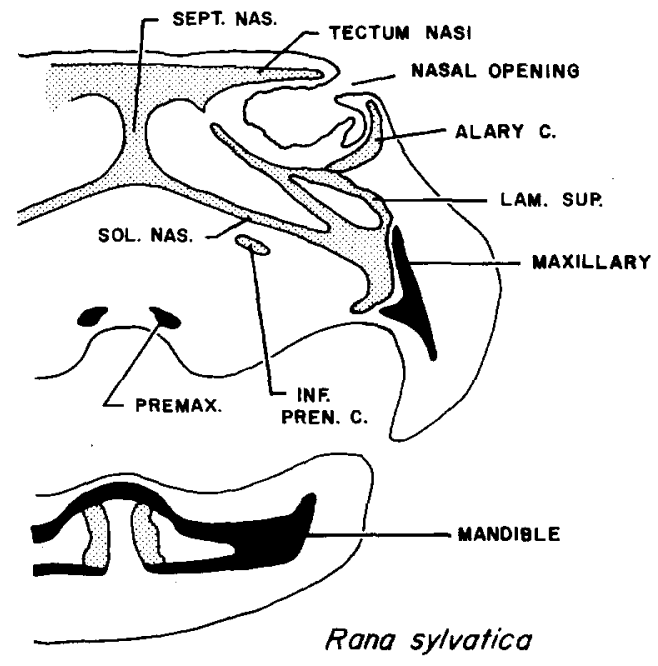

Fig. 2. Cross-section through the region of the external narial opening of Rana sylvatica (KU 186908). Bony structures are shown in solid black; cartilaginous areas are shaded. No muscles appear in the section. Abbreviations: Sept. nas., nasal septum; C., cartilage; Lam. sup., laminae superior; Inf. pren., inferior prenasal; Premax., premaxillae. 


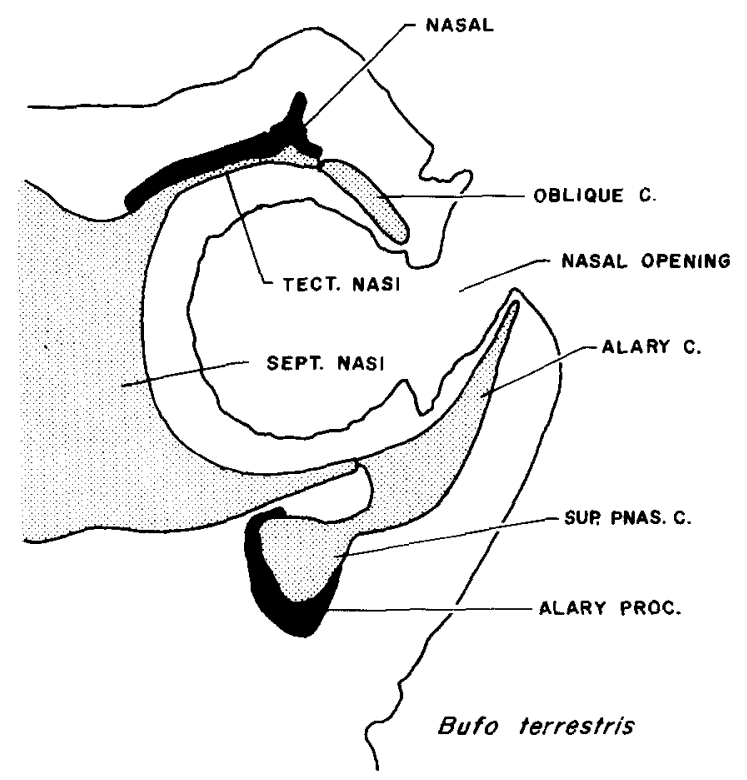

Fig. 3. Cross-section through the region of the external narial opening in Bufo terrestris (KU 186953; female). Bony structres are shown in solid black; cartilaginous areas in stipple. No muscles appear in the section. Abbreviations: C., cartilage; Tect. nasi, tectum nasi: Sept. nasi, nasal septum; Sup. pnas. C., superior prenasal cartilage.

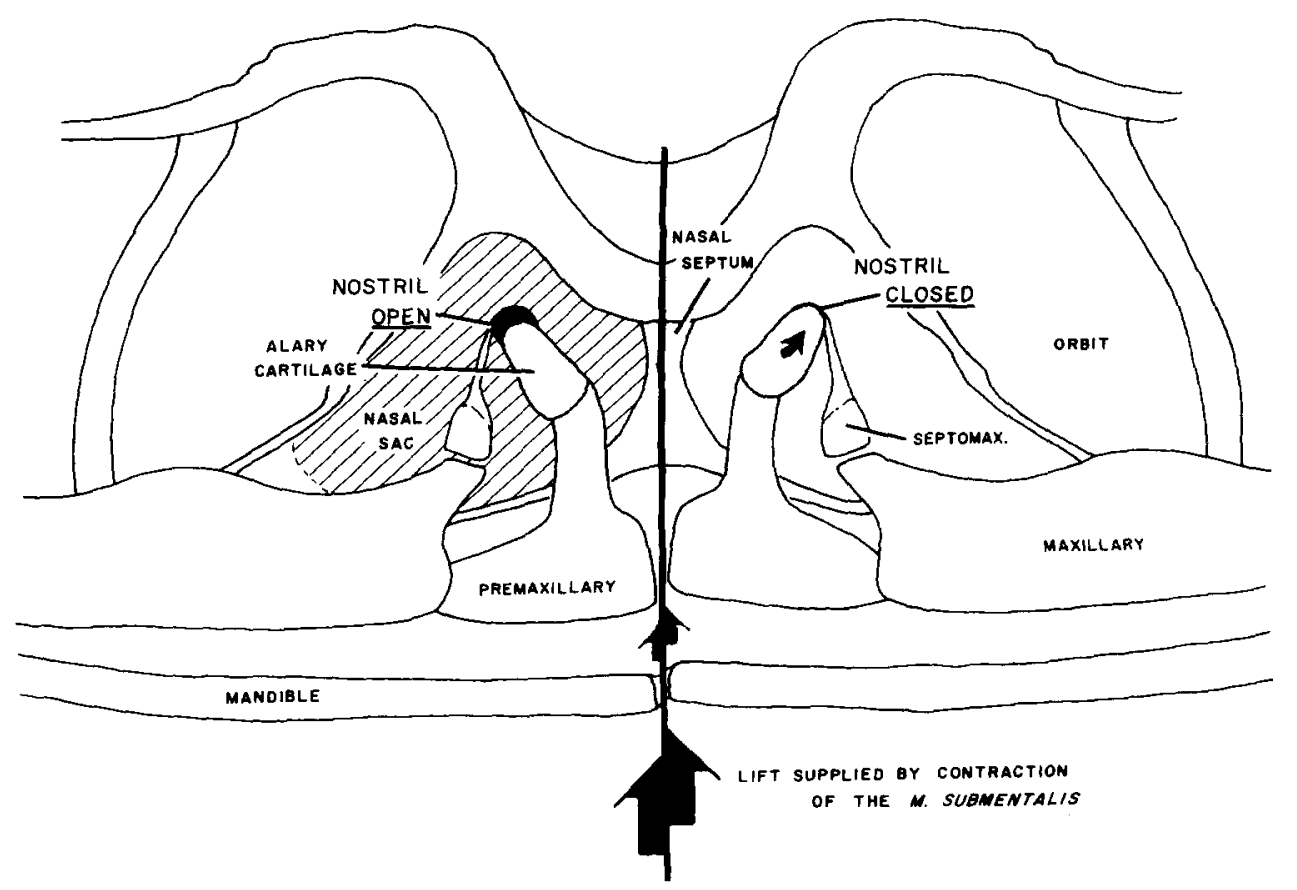

Fig. 4. Diagram to show reconstruction of narial region of Bufo marinus in front view. Left nostril open, right nostril closed. 
recessus sacciformis. Their existence, and even more their distribution, among the anurans remains to be checked. Also important in this context is that the linkage patterns observed in different anuran species differ in various complex ways (figs. 2-4), for instance in species in which the external nares lie at the tip of the snout, far anterior to the mandibular symphysis and even further anteriorly to the position of the M. submentalis. Clearly, much amphibian diversity remains to be explored.

\section{References}

Bruner, H. L. (1901). The smooth facial muscles of Anura and Salamandrina. Morphol. Jahrb. 29(3): $317-363$.

Bruner, H. L. (1914a). The mechanism of pulmonary respiration in amphibians with gill clefts. Morphol. Jahrb. 48(1): 63-82.

Bruner, H. L. (1914b). Jacobson's organ and the respiratory mechanism of amphibians. Morphol. Jahrb. 48(1): 157-165.

Clark, B. D., C. Gans and H.I. Rosenberg (1978). Air flow in snake ventilation. Respir. Physiol. 32: 207-212.

De Jongh, H. J. and C. Gans (1969). On the mechanism of respiration in the bullfrog, Rana catesbeiana: A reassessment. J. Morphol. 127: 259-290.

Dugès, A. (1834). Recherches sur l'Ostéologie et la Myologie des Batraciens à leurs différents Ages. Paris, Baillière.

Ecker, A. (1889). The Anatomy of the Frog. 2nd Ed. Oxford, Clarendon Press. [Translation by G. Haslam.]

Gans, C. and B. D. Clark (1978). Air flow in reptilian ventilation. Comp. Biochem. Physiol. 60A: 453-457.

Gans, C. and G.C. Gorniak (1980). Electromyograms are repeatable: Precautions and limitations. Science 210: 795-797.

Gans, C. and G.C. Gorniak (1982). Protrusion of the tongue in marine toads (Bufo marinus). Am. J. Anat. 163: 195-222.

Gaupp, E. (1896). Zur Lehre von dem Athmungsmechanismus beim Frosch. Arch. Anat. Physiol., Anat. Abth. 1896: 239-268.

Gaupp, E. (1898-1904). A. Ecker und R. Wiedersheim's Anatomie des Frosches. 3 Vols. Braunschweig, Vieweg.

Jones, D. R. (1970). Experiments on amphibian respiratory and circulatory systems. In: Experiments in Physiology and Biochemistry. Vol. 3, edited by G. A. Kerkut. London and New York, Academic Press.

Shinkai, K. and T. Narita (1957). Electromyographical studies on toads respiratory movements. Nagoya J. Med. Sci. 19: 1-6.

West, N. H. and D. R. Jones (1975). Breathing movements in the frog Rana pipiens. I. The mechanical events associated with lung and buccal ventilation. Can. J. Zool. 53: 332-344.

William, P. E. and G. Goldspink (1971). Longitudinal growth of striated muscle fibers. J. Cell. Sci. 9: 751-767. 